\title{
50 ANOS DE PÓS-GRADUAÇÃO EM DIREITO NO BRASIL: PONTO DE PARTIDA E UM OLHAR PARA O FUTURO
}

\author{
Fernando Facury Scaff
}

Introdução

Este trabalho tem uma dupla finalidade: apresentar algumas linhas sobre os primeiros 50 anos de estudos pós-graduados no Brasil na área jurídica após a estruturação efetuada pelo Parecer Sucupira, bem como sugerir caminhos a serem trilhados no porvir, de modo a sanar alguns pontos que são identificados e que merecem reflexão por parte da comunidade acadêmica envolvida no âmbito da gestão e da pesquisa jurídica de pósgraduação.

1. Ponto de partida: o marco histórico do Parecer Sucupira

Em 2021 registra-se a comemoração dos 50 anos de pós-graduação em Direito no Brasil e, concomitantemente, da implantação do PPGD - Programa de PósGraduação em Direito da Universidade de São Paulo, após a grande reformulação criada pelo Parecer do Conselho Federal de Educação 977/65, exarado em 03/12/65, conhecido na área educacional pelo nome de seu subscritor, Newton Sucupira. ${ }^{2}$

Antes não havia clareza sobre o que seriam cursos de pós-graduação, especialização, aperfeiçoamento e extensão que eram previstos no art. 69 da Lei de Diretrizes e Bases da Educação Nacional (Lei 4.024/61, já revogada). Até aquela época, praticamente não existiam cursos regulares de pós-graduação no Brasil, servindo o curso de graduação para formar o profissional, o cientista e o tecnólogo. Apenas algumas faculdades concediam títulos acadêmicos, como o de livre docente, sem que tivesse havido necessariamente um curso regular para sua formação. A pós-graduação, segundo Sucupira, permitiria que as Universidades se transformassem efetivamente em um centro

\footnotetext{
Professor Titular da Faculdade de Direito da Universidade de São Paulo, atualmente no exercício da Presidência da Comissão de Pós-Graduação da Faculdade (2018-2022) em conjunto com a Profa. Titular Ana Elisa Bechara. Representante da Área de Direito junto a CAPES (2002-2004); Membro e exPresidente da Comissão de Especialistas no Ensino de Direito, da SESU - Secretaria de Ensino Superior/ MEC (2000-2002); Membro da Comissão de Direito do Exame Nacional de Cursos (Provão)/MEC (19972001). Professor Titular aposentado da Universidade Federal do Pará.

2 As referências ao Parecer Sucupira foram retiradas do texto publicado na Revista Brasileira de Educação n. 30, set/out/nov/dez 2005, p. 162-173. Disponível em: https://www.scielo.br/pdf/rbedu/n30/a14n30.pdf. Acesso em: 15 mar. 2021.
} 
irradiador de ciência e cultura, e permitissem a formação de qualificados professores universitários.

No Parecer Sucupira consta, como princípio, que "a pós-graduação tornase, assim, na universidade moderna, cúpula dos estudos, sistema especial de cursos exigido pelas condições da pesquisa científica e pelas necessidades do treinamento avançado. O seu objetivo imediato é, sem dúvida, proporcionar ao estudante aprofundamento do saber que lhe permita alcançar elevado padrão de competência científica ou técnicoprofissional, impossível de adquirir no âmbito da graduação. Mas, além destes interesses práticos imediatos, a pós-graduação tem por fim oferecer, dentro da universidade, o ambiente e os recursos adequados para que se realize a livre investigação científica e onde possa afirmar-se a gratuidade criadora das mais altas formas da cultura universitária". ${ }^{3}$

Dos títulos anteriormente concedidos como de livre docência ou de doutorado, restou apenas a memória e o louvor a alguns docentes ou profissionais de qualidade, que os obtinham muito mais pelos méritos de sua formação pessoal do que pela adesão a um método científico reconhecido. Isso era realizado através de fórmulas pouco transparentes à sociedade, estabelecidas pelas faculdades ou universidades isoladamente, sem um procedimento que fosse padronizado e permitisse comparabilidade. A obtenção de formação qualificada em diversas áreas do conhecimento só poderia advir através de estudos sistematizados realizados em universidades estrangeiras, não havendo, no Brasil, um sistema nacionalmente integrado de pós-graduação.

Daí a surpresa contemporânea quando se verifica que vários mestres do passado, reconhecidos como destacados professores, não possuíam doutorados formais, mas eram reconhecidos como tal pelo meio jurídico como um todo. Um bom exemplo desse período histórico é Miguel Reale (pai), eminente professor catedrático da Faculdade de Direito da USP, notável filósofo e idealizador da teoria tridimensional do Direito, ex-Reitor da USP, que, nessa função, aprovou o Regulamento do Programa de Pós-Graduação em Direito dessa Universidade através da Portaria 1211, de 25/06/70 (DOE-SP 30/06/70, pág. 46). Os exemplos poderiam se multiplicar em todo o Brasil, de modo icônico, como este. Tais docentes iniciaram a pós-graduação no Brasil, e foram os primeiros formadores dentro desse sistema.

É desse marco inicial do Parecer Sucupira que se reestruturou a pósgraduação no Brasil, e, obviamente, também a pós-graduação em Direito, fazendo-o em dois níveis, mestrado e doutorado, sendo que, "embora hierarquizados, o mestrado não constitui condição indispensável à inscrição no curso de doutorado", uma vez que “o mestrado pode ser encarado como etapa preliminar na obtenção do grau de doutor ou

\footnotetext{
Parecer Sucupira, ob. cit, p. 164.
} 
como grau terminal". Já o doutorado, "tem por fim proporcionar formação científica ou cultural ampla e aprofundada, desenvolvendo a capacidade de pesquisa e poder criados nos diferentes ramos do saber". ${ }^{4}$

O programa de estudos em qualquer desses níveis deve se caracterizar "por grande flexibilidade, deixando-se ampla liberdade de iniciativa ao candidato que receberá assistência e orientação de um diretor de estudos", podendo ser realizado através de "seminários, trabalhos de pesquisa, ou atividades de laboratório com a participação ativa dos alunos". 5

E isso deveria ocorrer em duas fases: "a primeira fase compreende principalmente a frequência às aulas, seminários culminando com um exame geral que verifique o aproveitamento e a capacidade do candidato. No segundo período o aluno se dedicará mais à investigação de um tópico especial da matéria de opção, preparando a dissertação ou tese que exprimirá o resultado de suas pesquisas". ${ }^{6}$

Para a obtenção do grau de mestre, o candidato deve defender dissertação na qual revele "domínio do tema escolhido e capacidade de sistematização", e para a obtenção do grau de doutor requer-se defesa de tese, "que represente trabalho de pesquisa importando em real contribuição para o conhecimento do tema". ${ }^{7}$

O Parecer Sucupira ainda destaca que "o mesmo curso de pósgraduação poderá receber diplomados provenientes de cursos de graduação diversos, desde que apresentem certa afinidade", ${ }^{8}$ o que aponta, desde então, para a necessária interdisciplinariedade exógena às disciplinas estudadas, o que é extremamente positivo.

O Parecer Sucupira organizou todo o sistema de pós-graduação no Brasil, e a área do Direito seguiu esse padrão, como se vê desde a fundação do Programa de Pós-Graduação em Direito da USP, criado em 1969, e iniciado em 1971, há cinquenta anos atrás, funcionando de modo ininterrupto, e que é a alma mater de quase todos os Programas de Pós-Graduação em Direito do Brasil, hoje com mais de 100 cursos.

2. O papel dos docentes de pós-graduação

Considere-se que as Faculdades de Direito possuem uma característica ímpar dentre todas as áreas do conhecimento, pois exclusivamente delas saem os trabalhadores que comporão os pilares do Estado de Direito, que são os membros do Poder Judiciário, do Ministério Público, da Advocacia (pública e privada) e do aparato

\footnotetext{
Parecer Sucupira, ob. cit, p. 172.

Parecer Sucupira, ob. cit, p. 172.

Parecer Sucupira, ob. cit, p. 171.

Parecer Sucupira, ob. cit, p. 172.

Parecer Sucupira, ob. cit, p. 172.
} 
policial - todos frequentaram os cursos jurídicos oferecidos pelas IES públicas e privadas credenciadas no país. Delas também saem os docentes que retroalimentam estas Instituições de Ensino.

Com a nova conformação realizada pelo Parecer Sucupira, a pós-graduação tornou-se o lugar de formação dos formadores, isto é, foi criada uma carreira docente, passando paulatinamente a ser exigido das Instituições de Ensino que contratassem como docentes quem tivessem o grau de mestre ou de doutor, ao invés de o fazer apenas em razão de qualificações profissionais, notadamente, na área jurídica, magistrados, promotores e advogados.

Os docentes são as peças mais importantes de toda essa engrenagem de educação e ensino jurídicos, ${ }^{9}$ pois formarão as condições e apresentarão as experiências capazes de identificar o justo, dentro da ordem jurídica, e apresentá-las aos alunos de graduação ao longo de cinco anos de convívio, nem sempre amigável e fraterno. A função docente é uma das mais difíceis em toda essa engrenagem, pois implica em um processo de ensino e aprendizagem, onde um dos atores tem que primordialmente se comprometer a ensinar, e, o outro, primordialmente em querer aprender. Trata-se de uma relação de mão dupla, pois os docentes também aprendem com os alunos.

Dentro da profissão jurídica docente existe um grupo que merece ser destacado: é o dos docentes de pós-graduação, em cursos de mestrado e doutorado. Estes são o locus da formação dos formadores, isto é, os mestrandos e doutorandos de hoje serão os qualificados professores das faculdades de Direito de amanhã. Tais professores têm sua importância e responsabilidade redobradas no âmbito da educação e do ensino jurídico, pois o que ensinarão será projetado além das atuais salas de aula, na formação daqueles que formarão os demais alunos para as profissões jurídicas. Os docentes de pós-graduação são os jardineiros que cuidam das sementes que farão germinar outros jardins no futuro.

Exatamente por isso que o nível de comprometimento e de pesquisa no âmbito da pós-graduação deve ser muito mais intenso do que na graduação, possuindo tais docentes redobrada importância dentro do sistema, pois eles não apenas ministram aulas para os futuros profissionais da área jurídica, mas o fazem para quem formará os futuros formadores.

Para tanto, é importante a dimensão da pluridisciplinaridade, rompendo os esquemas clássicos da graduação, pois necessariamente devem ser mesclados saberes de diversas disciplinas, sejam ou não jurídicas. É a pesquisa realizada no âmbito da pós-

9 SCAFF, Fernando Facury. Por que estudar direito nos dias atuais: entre o ensino e a educação jurídica. Revista Fórum de Direito Financeiro e Econômico - RFDFE, ano 9, n. 17, p. 9-17, mar./ago. 2020 Disponível em: https://www.forumconhecimento.com.br/periodico/143/41968/92225. Acesso em: 26 mar 2021. 
graduação que alimentará as disciplinas de graduação e de pós-graduação das diversas faculdades de Direito.

É adequado na área jurídica aliar o perfil profissional ao lado do perfil acadêmico, pois permite unir os aspectos teóricos aos práticos, o que enriquece o ensino e a educação, sendo necessário, contudo, que o docente saiba diferenciar sua posição enquanto profissional e acadêmico, pois possuem distintos perfis. É o conhecimento que deve ser compartilhado, e não servir de instrumento de doutrinação profissional.

Sobre esse tema existe um aspecto bastante positivo na Lei de Diretrizes e Bases da Educação (LDB), que obriga as Instituições de Ensino Superior a ter, no mínimo, um terço de seu corpo docente composto por mestres e doutores para serem consideradas como Universidades.

A despeito dos aspectos positivos desta norma, ela contém um aspecto perverso, pois torna indistinto o grau, ao estabelecer que podem compor este terço tanto mestre quanto doutores. ${ }^{10}$ Isso, no âmbito do ensino privado, torna privilegiada a contratação de mestres em detrimento da contratação de doutores, pois, dentro do quadro de pessoal dessas Instituições, os mestres têm remuneração de menor monta, o que traz uma indicação negativa para o desenvolvimento do conhecimento jurídico, estimulando a contratação do grau intermediário de pós-graduação.

3. Um olhar para o futuro: desafios a serem vencidos

Considerada a posição atual dos diversos Programas de Pós-Graduação em Direito em nosso país após 50 anos do Parecer Sucupira, quais pontos devem merecer atenção no porvir?

\section{a) Reafirmação da posição doutrinária em face das decisões dos Tribunais}

Um dos aspectos mais importantes é o da reafirmação da posição doutrinária em face das decisões dos Tribunais.

É necessário haver o deslocamento do olhar, de modo a que a jurisprudência não seja o guia das pesquisas, mas seu objeto, isto é, o que os Tribunais decidem deve ser o objeto das análises críticas por parte da doutrina, que pode assentir ou não com o que tiver sido julgado, mas não se pode considerar como verdade jurídica inabalável o que constam dessas decisões. Não se pode jamais ignorá-las, mas a jurisprudência não é

10 LDB, Lei 9394/96: “Art. 52. As universidades são instituições pluridisciplinares de formação dos quadros profissionais de nível superior, de pesquisa, de extensão e de domínio e cultivo do saber humano, que se caracterizam por: II - um terço do corpo docente, pelo menos, com titulação acadêmica de mestrado ou doutorado". 
o Direito - ela diz sobre o Direito no caso concreto, e, ainda mais, deve se submeter ao crivo doutrinário para ser possível se conhecer de seus acertos ou erros. Este deve ser a inafastável e primeira função do ensino e da pesquisa no âmbito da pós-graduação.

É sempre adequado considerar que tais decisões, via de regra, deliberam sobre casos concretos, que são terminativos para as partes, mas não vinculam as análises jurídicas, de modo a transformar-se em doutrina e se posicionando como uma visão completa sobre o Direito.

Trata-se de uma questão de método, pois a jurisprudência parte da análise de cada caso individualizado e aplica o conhecimento geral, doutrinário, a ele - logo, trabalha do individual para o geral. Por outro lado, a doutrina parte da análise geral, holística, do Direito, sem se debruçar sobre as incontáveis peculiaridades dos casos concretos que podem surgir a partir dos debates judiciais, e só quando estes ocorrem é que aplica a teoria em sua solução - logo, trabalha do geral para o particular.

Em síntese: a jurisprudência é um campo de pesquisa, e não obrigatoriamente uma fonte para a doutrina. A doutrina deve embasar a jurisprudência, e não o contrário. A doutrina deve doutrinar, pois, não sendo assim, dever-se-iam fechar as Faculdades e os Programas de Pós-Graduação e colocar os alunos para aprender Direito assistindo as sessões dos Tribunais, o que seria uma estultice.

\section{b) Olhar para a pesquisa aplicada, sem esquecer da pesquisa pura}

Como ciência social aplicada, o Direito deve considerar em suas pesquisas o enfrentamento dos problemas sociais e econômicos de uma comunidade, seja local, regional, nacional ou internacional, buscando resolver seus problemas concretos de forma contextualizada e historicizada, e não questões desconectadas da realidade.

São tais espécies de problemas que devem nortear os estudos jurídicos, e não o singelo diálogo entre posições doutrinárias sem conexão com a realidade. Discussões sobre conceitos são importantes, desde que sejam dirigidos para a solução de problemas, e não para afirmação meramente teórica de posições individuais.

Para isso, é necessário reforçar os aspectos metodológicos da pesquisa jurídica, o que não se restringe apenas a saber fazer as transcrições ou as referências bibliográficas através do sistema ABNT. É muito mais do que isso.

Ao se pensar a partir de problemas, com o prévio levantamento do conhecimento existente, em especial das produções acadêmicas mais recentes, o texto acadêmico a ser produzido deve cogitar hipóteses que aportarão possíveis soluções para o problema existente. Esse tipo de análise afasta os trabalhos que são meras descrições de objetos, ou com um enorme desfile de autores citados, sem chegar a nenhum avanço 
ou conclusão que espelhe algo novo em termos de avanços científicos ou soluções para os problemas apontados ou existentes.

Isso está conectado ao item anterior, sobre o papel da doutrina auxiliando a jurisprudência, e não a reboque dela. Quais alternativas jurídicas são possíveis para solucionar um problema que chegou ou chegará ao Poder Judiciário? Ou para algum problema que poderá ser solucionado através da via legislativa ou normativa? Estarão as normas vigentes contemplando soluções para os problemas existentes?

Raciocinar através do método científico de problemas $x$ soluções é uma alternativa para evitar os trabalhos redundantes e aqueles em que são discutidos assuntos de pouca relevância social.

Esse repto à pesquisa aplicada não afasta a necessidade de pesquisa pura, isto é, aquela que dará base para outras pesquisas com maior grau de concretude. Nesse sentido, há espaço para análises doutrinárias inovadoras, teóricas, sobre diversos campos do conhecimento jurídico, como na área de filosofia ou de teoria do direito. Não fosse assim, dever-se-ia abandonar os estudos de Kant ou de Dworkin, o que não teria sentido. Porém, é necessário afastar a mera reprodução do saber já posto, que é de todos conhecido, e partir para novas dimensões utilizando a base já existente. Não adotar tais parâmetros será apenas reproduzir o que já existe, e esse, definitivamente, não é o papel da pós-graduação em Direito.

\section{c) Organização através de áreas e linhas de pesquisa, e não por departamentos}

Os itens acima apontam para outra questão, que é o papel dos Programas de Pós-Graduação em Direito na identificação das dificuldades sociais e nos desafios para sua ultrapassagem.

Originalmente a pós-graduação era organizada dentro do contexto dos departamentos, tal qual ocorria em diversas Faculdades de Direito. A despeito de ser uma forma de organização acadêmica válida para fins administrativos, e possivelmente para o ensino de graduação, não encontra respaldo nas atividades de pesquisa, ínsitas aos PPGD, pois estes requerem uma transversalidade no conhecimento, como promovendo um corte transversal epistemológico. Como estudar questões que envolvem direitos humanos de forma isolada de aspectos envolvendo diversas outras áreas do saber jurídico, como o direito internacional, do Estado, constitucional, penal, processual, financeiro, civil etc.? Como estudar o orçamento público em todas suas dimensões sem ter conhecimento de outras áreas?

Estudos pós-graduados devem ser necessariamente interdisciplinares e, muitas vezes, multidisciplinares, e a organização acadêmica de forma departamental muitas vezes inibe essa interconexão. 
Nesse sentido, organização da pós-graduação em áreas do conhecimento, e, de forma subsidiária, em linhas de pesquisa, é muito mais adequada e favorece o surgimento de grupos de pesquisa, os quais desenvolvem projetos de pesquisa, centrados na solução de problemas específicos, com a característica de terem início, meio e fim, de acordo com as etapas de seu desenvolvimento. Tais projetos de pesquisa é que, por sua vez, permitirão que surjam disciplinas próprias de pós-graduação, diversas daquelas ministradas no âmbito dos estudos de graduação. Assim, ao invés de se ministrar a disciplina direito administrativo I e II, como no âmbito da graduação, pode-se, com maior liberdade acadêmica, criar disciplinas que estudem a função das agências reguladoras, envolvendo tanto a área de direito administrativo, quanto a de direito econômico e a de direito societário, as quais, sob um modelo de graduação, ficariam isoladas em diferentes departamentos. Esta interação entre diferentes áreas do saber é uma das características próprias da pós-graduação, e sua organização sob tais regras permite maior flexibilidade acadêmica.

É dentre deste contexto organizacional que tais Programas, em conjunto com o corpo docente que os compõe, devem identificar as diversas lacunas existentes nas áreas de conhecimento que lhes são afetadas, e facilitar a construção de grupos de pesquisa para sua análise. Desse primeiro passo, deve-se seguir toda a construção teórica mencionada, isto é, formulação de projetos de pesquisa, disciplinas de pós-graduação, publicações de papers, dissertações e teses.

Daí a importância da realização de eventos acadêmicos, envolvendo não só os docentes de cada área ou linha de pesquisa, mas também os discentes e egressos, fortalecendo a pesquisa e criando novos projetos - sempre com os olhos voltados à solução de problemas da sociedade, sob o prisma jurídico. Apresentação de trabalhos pelos discentes e publicação de papers conjuntos é sempre uma forma de fortalecer tais grupos, devendo-se evitar o efeito carona, que pode ocorrer - uns elaboram o texto e outros o assinam em conjunto.

A organização da pós-graduação requer flexibilidade para o surgimento de novos grupos de pesquisa e o aprofundamento de questões teóricas que envolvam a pesquisa pura e a aplicada, em busca de soluções para os ingentes problemas sociais existentes.

\section{d) Dimensão Pluridisciplinar: Estudos entrópicos, interdisciplinares, multidisciplinares e transdisciplinares}

$\mathrm{Na}$ linha da crítica à forma de organização departamental para fins de pós-graduação, deve-se destacar a questão do relacionamento com outras áreas do conhecimento. 
Vê-se em muitos estudos e disciplinas na pós-graduação em Direito uma espécie de entropia, com o olhar voltado apenas para sua específica área de conhecimento. De certa forma isso é positivo, porém inegavelmente incompleto. É positivo porque a especialização do conhecimento é necessária e o faz avançar naquele específico campo. Todavia, é incompleto, porque se perde a noção do todo, do contexto da análise em suas múltiplas dimensões.

Sendo o Direito um conhecimento vinculado às humanidades, se caracterizando como uma área das ciências sociais aplicadas, é até redundante destacar que suas pesquisas devem ser voltadas ao estudo do homem, e não apenas das normas jurídicas - estas existem para permitir uma adequada convivência humana em sociedade. Logo, no centro dos estudos deve estar o homem em sociedade, cuja regulação se dá através de normas jurídicas, e isso necessariamente amplia o foco das análises. É insuficiente o estudo das normas jurídicas em si e por si (entropia) - é preciso destacar que elas existem em razão, e para viabilizar, a convivência humana em sociedade.

Daí surgem diferentes dimensões para o estudo jurídico, afastando os estudos entrópicos, acima referidos.

É possível aliar duas ou mais áreas de disciplinas jurídicas, como no exemplo acima referido quanto ao estudo das agências reguladoras, em diferentes áreas do conhecimento jurídico. A isso comumente se denomina de interdisciplinaridade endógena, isto é, dentro da mesma área.

É também possível aliar estudos entre diferentes áreas do conhecimento, o que necessariamente envolve docentes e pesquisadores de campos diversos. Exemplos não faltam, como no direito penal aliado à medicina, ou no direito financeiro conectado à ciência política. Nesta hipótese, se terá dois ou mais profissionais abordando aspectos a partir de seus referenciais teóricos, e os alunos e a comunidade acadêmica será brindada com diversos pontos de vista sobre a mesma matéria. Trata-se aqui de um passo mais avançado, que é o da interdisciplinaridade exógena, ou multidisciplinaridade.

Outra possibilidade, de muito mais difícil concretização, ocorre quando são aliados saberes de áreas distintas, porém voltados para a construção de novos saberes, proporcionando um salto no conhecimento. Cada docente ou pesquisador não fala a partir apenas de sua própria experiência e do seu conhecimento acadêmico em sua área específica, mas está aberto à colaboração, compreensão da dimensão do outro e criação de novos saberes que aliem os diversos campos do conhecimento. A isto se denomina usualmente de transdisciplinaridade. São quebradas as barreiras tradicionais de cada área ou subárea do conhecimento a fim de criar algo que seja realmente novo no campo de pesquisa.

As dificuldades para o efetivo exercício dessa transdisciplinaridade são enormes, e é um desafio para os PPGDs. Como trabalhar estas novas fronteiras do 
conhecimento aliando os avanços tecnológicos com o Direito, que, de certo modo quebra as estreitas fronteiras territoriais? O direito tributário, por exemplo, que é essencialmente territorializado, isto é, exercido dentro de um Estado nacional, vem sendo fortemente impactado pela desmaterialização dos serviços, que podem ser prestados on line a partir de qualquer lugar do mundo, inclusive com a mudança das sedes das empresas para paraísos fiscais - como os Estados nacionais podem tributar esses serviços prestados e essa riqueza haurida? Não é suficiente a análise estanque do direito tributário para resolver esse problema, sendo necessário aliar múltiplas áreas do conhecimento para isso, não só do direito (financeiro, do Estado, constitucional etc.), como de outras áreas das humanidades (economia, contabilidade etc.), mas também da tecnologia. Os exemplos poderiam se multiplicar.

Os PPGDs devem se organizar de modo a favorecer estes diversos âmbitos pluridisciplinares, os quais devem ser ampliados e valorizados, sem perder de vista que, ao fim e ao cabo, se trata de pós-graduação em Direito, e não em áreas correlatas, isto é, não se pode perder de vista a área de origem dos estudos, mas se deve estar aberto às suas múltiplas conexões.

\section{e) Tradicional divulgação através de livros e não de revistas científicas}

A forma de organização dos saberes no âmbito da pós-graduação nos leva a outro aspecto que aflige a área jurídica, que é o da veiculação da produção acadêmica.

Tradicionalmente o conhecimento jurídico é transmitido através de livros e não de revistas científicas, e isso é algo que deve ser enfrentado, embora não se saiba muito bem como o fazer.

Livros demandam muito tempo para serem elaborados e publicados, o que os afasta do conhecimento de ponta, pois, uma obra específica, elaborada por um único autor, sobre um tema que seja candente em determinado momento, só vem a lume passado aquele evento, tornando-se, quando muito, um livro de referência naquela matéria, e isolado em poucas bibliotecas. Mesmos os manuais e os cursos, que são extremamente importantes para os estudos de graduação e possuem menor importância nos estudos pós-graduados, necessitam de atualização constante, sob novas edições, para poder acompanhar os fatos e a produção bibliográfica e jurisprudencial em sua temática.

Uma forma muito usual na área jurídica para agilizar a comunicação científica é a produção de livros coletivos, nos quais um ou mais coordenadores submetem a análise de determinado tema a um grupo qualificado, que produz textos envolvendo aquela matéria, o qual se torna uma obra de referência sob aquele assunto. Assim, ao invés de serem organizadas revistas cientificas acerca de determinadas áreas do conhecimento, como, por exemplo, federalismo, elaboram-se diversos e sucessivos livros coletivos sobre 
diferentes aspectos do federalismo. A produção de livros coletivos, muito usual na área jurídica, esvazia a importância das revistas científicas, e pretensamente, ocupa seu espaço.

Todavia, sabe-se que não é bem assim, em especial quando se observa outras áreas do conhecimento, como nas ciências biológicas, nas quais a publicação de relevo está nas revistas científicas ranqueadas por cada ramo específico, e não por livros. $\mathrm{O}$ ranking das revistas científicas decorre de sua importância e na amplitude de sua divulgação, dentre outros critérios estabelecidos pelos cientistas de cada área.

A divulgação do conhecimento através de revistas científicas possui vantagens, dentre elas: (1) é mais ágil do que a produção de livros, o que acarreta a chegada do conhecimento aos utentes de forma up to date com os fatos analisados; (2) os textos publicados são referendados por pares, através da sistemática de blind review, ou ainda, de double blind review, o que confere maior confiabilidade ao que está sendo publicado e afasta voluntarismos e compadrios; (3) afasta a necessidade de múltiplas edições, muitas vezes anuais, o que gera um esforço hercúleo e muitas vezes vão; (4) dá à publicação uma perenidade datada, vinculada aos fatos e condições durante as quais aquela matéria foi analisada, sendo que eventuais atualizações serão objeto de novos artigos que demonstrem a diferença entre a análise anterior e a mais recente, sem a necessidade de expor tudo novamente.

A grande desvantagem do sistema de revistas científicas é que, como regra, as mais relevantes cobram para que os artigos a ela submetidos sejam analisados, o que não garante sua publicação, pois podem ser refutados. De certa forma esse procedimento mercantiliza a produção acadêmica, pois só as Instituições ou os pesquisadores que possuem fundos financeiros é que conseguem acesso aos principais veículos de divulgação científica.

Na área jurídica a explosão numérica de revistas científicas não acompanhou o destaque acadêmico que possui em outras áreas do saber. São pouquíssimas as revistas jurídicas que possuem efetivo blind review, e, ao que se saiba, nenhuma cobra para analisar os artigos a ela submetidos. $\mathrm{Na}$ verdade, cumprem requisitos que foram exigidos no final do século passado para a avaliação de cursos de graduação por parte do MEC (Portaria 1886/94), ${ }^{11}$ o que foi um erro, pois as multiplicou sem a correspondente qualificação e importância dentro do sistema. Uma vez criadas, estas revistas passaram a ser perenizadas e se tornaram um instrumento útil para cumprir as sucessivas alterações de Diretrizes Curriculares do Curso de Graduação em Direito, ${ }^{12}$ sem a correspondente concretização de sua preocupação científica.

11 Portaria 1886/94, revogada pela letra "c", do item VIII, que trata "da pesquisa", na qual se exigia "a manutenção de periódicos para publicação da produção intelectual de seus corpos docente e discente."

12 A atual, Resolução 5/18, exige no art. $2^{\circ}, \S 1^{\circ}$, que os cursos de graduação tenham, como elemento estrutural, 
Atualmente, como exposto, são os livros que possuem destaque dentro da produção acadêmica dos PPGD, embora as regras de avaliação da CAPES, formatadas para todas as áreas do conhecimento científico, avaliem e atribuam pontos para a produção acadêmica veiculada através de revistas científicas. Isso acarreta uma enorme dificuldade acadêmica e operacional para os Programas de Pós-Graduação em Direito, ainda não devidamente resolvida no âmbito das sucessivas representações da área do Direito junto à Capes, espécie de agência reguladora da pós-graduação no Brasil, pois confronta uma tradição da área jurídica.

\section{f) Expansão acelerada de PPGD e a "inflação de credenciais"}

As considerações acima efetuadas conduzem a preocupações com a exagerada expansão da pós-graduação em Direito no Brasil e aquilo que se denomina de inflação de credenciais, acarretando sua desvalorização e a diminuição da vantagem esperada no mercado de trabalho, inclusive no acadêmico.

Não há dúvida que os problemas brasileiros são vastíssimos e vivenciados por uma sociedade excludente e profundamente desigual, social e economicamente, e que isso demanda um esforço ingente da área jurídica para sua compreensão e ultrapassagem. Todavia, observando os PPGDs existentes no Brasil, constata-se que muitos possuem áreas de conhecimentos superpostos e linhas de pesquisa tradicionais, que conduzem a resultados pouco aderentes aos desafios apresentados pela realidade brasileira.

Normas de direito educacional estabeleceram determinado número de cursos de pós-graduação estrito senso para que as unidades acadêmicas conseguissem ser reconhecidas como centros universitários ou universidades, ${ }^{13}$ o que, de certa forma, contribuiu de forma maléfica para a expansão descoordenada e descontrolada do sistema, através da pressão por aprovação de PPGD sem qualquer compromisso científico, observando ainda que o foco na área jurídica se deu em razão do baixo custo em sua implantação e manutenção. Assim, para estas Instituições de Ensino Superior, a aprovação de PPGD se torna uma espécie de requisito a ser ultrapassado, sem compromisso com a pesquisa, pura ou aplicada, e a inovação jurídica.

dentre outros "IX - incentivo, de modo discriminado, à pesquisa e à extensão, como fator necessário ao prolongamento da atividade de ensino e como instrumento para a iniciação científica".

13 Decreto 9235/17: “Art. 17. As IES privadas poderão solicitar recredenciamento como universidade, desde que atendam, além dos requisitos gerais, aos seguintes requisitos: VII - oferecerem regularmente quatro cursos de mestrado e dois cursos de doutorado reconhecidos pelo Ministério da Educação". Antes, o Decreto 5773/06, já revogado, previa: "Art. 16. O plano de desenvolvimento institucional deverá conter, pelo menos, os seguintes elementos: IX - oferta de cursos e programas de mestrado e doutorado". 
Por outro lado, muitos dos alunos de PPGD também não possuem tal engajamento científico, acarretando que a obtenção dos graus acadêmicos de mestre e de doutor acabam por ser uma forma de singela ascensão social ou profissional em carreiras não acadêmicas. É inegável que ter um juiz, promotor ou advogado que seja mestre ou doutor em Direito aponta para uma maior qualificação profissional, porém isso não implica em ampliar sua análise científica acerca do específico objeto de seu trabalho ou em compromisso acadêmico com os estudos jurídicos voltados à solução de problemas sociais.

Educação, conceito mais amplo do que ensino, deve ser incrementado em prol da sociedade e não apenas de um indivíduo isoladamente.

A expansão imoderada de PPGD no Brasil deve ser objeto de preocupações de todos os trabalhadores do setor jurídico, pois pode vir a ocorrer uma explosão de titulações com baixa qualificação, e isso ser reproduzido na sequência, causando malefícios de diversas naturezas. Isso foi visto no âmbito da graduação em Direito ao longo dos últimos vinte anos, com a criação de muitos cursos de baixo nível, nos quais um diploma de bacharel em Direito era obtido com muito pouco esforço, o que se refletiu em seu reduzido apreço no mercado das profissões jurídicas.

\section{g) Há distinção entre um saber profissional e um saber acadêmico no conhecimento} jurídico? Mestrados e Doutorados Profissionais

Neste tópico se insere um debate relevante, que tem sido deixado de lado nos últimos tempos.

O mestrado profissional, ou profissionalizante, como foi denominado em sua gênese, no final dos anos 90, tem por objetivo diferenciar os saberes acadêmicos dos profissionais, distinguindo e apartando tais campos de conhecimento. Basta ver as atuais regulamentações sobre a matéria, hoje envolvendo até mesmo doutorados profissionais, Resolução CNE/CES 7/17 e Portaria CAPES 60/19, nas quais constam os objetivos desses cursos. ${ }^{14}$

14 Portaria CAPES 60/19, Art. $2^{\circ}$ : I - capacitar profissionais qualificados para práticas avançadas, inovadoras e transformadoras dos processos de trabalho, visando atender às demandas sociais, econômicas e organizacionais dos diversos setores da economia; II - transferir conhecimento para a sociedade de forma a atender às demandas sociais e econômicas, com vistas ao desenvolvimento nacional, regional e local; III - contribuir para agregação de conhecimentos de forma a impulsionar o aumento da produtividade em empresas, organizações públicas e privadas; IV - atentar aos processos e procedimentos de inovação, seja em atividades industriais geradoras de produtos, quanto na organização de serviços públicos ou privados; V - formar doutor com perfil caracterizado pela autonomia, pela capacidade de geração e transferência de tecnologias e conhecimentos inovadores para soluções inéditas de problemas de alta complexidade em seu campo de atuação. 
Inegavelmente isso tem um campo próprio de atuação, que permite um diálogo mais próximo com as demandas profissionalizantes da sociedade, como se pode verificar na área das ciências biológicas, onde determinados saberes podem ser compartimentalizados, como, por exemplo, na criação de cursos específicos para hospitais, voltados ao atendimento dos doentes, ou para instrumentação em salas de cirurgia. Ou ainda, nas áreas tecnológicas, voltados para empresas e sistemas de tecnologia da informação. É possível até mesmo pensar em algo na área de humanidades, como no setor de comunicação sociais, dirigido às mídias sociais.

A questão que foi muito debatida, e que infelizmente não mais se discute, é se este tipo de distinção entre saberes acadêmicos e profissionais tem lugar na área jurídica. Haverá distinção entre um saber profissional e um saber acadêmico no conhecimento jurídico?

Entendo que não. Pode existir pesquisa mais voltada para questões concretas (pesquisa aplicada) ou pesquisa essencialmente teórica (pesquisa pura), mas não existem campos distintos entre esses dois saberes. Este é o ponto essencial para o debate.

Pode-se discutir a importância do sistema de cartórios de registro de imóveis como um instrumento de segurança jurídica, e isso será, ao mesmo tempo, profissional e acadêmico. Todavia, se o estudo se circunscrever à análise dos procedimentos cartoriais de rotina, isso poderá ser muitas coisas, mas não pesquisa. Este estudo pode se circunscrever em curso prático, rápido, instrumental, que pode ser atendido pelos cursos de pós-graduação lato sensu, como especialização ou aperfeiçoamento, que infelizmente perderam o apelo de mercado em razão da inflação de credenciais surgida nesse âmbito. Haverá pesquisa nesse campo ou meramente praticismo? Já pensaram um doutor profissional em práticas de registro cartorial?

Observe-se que a legislação que rege esses cursos profissionais permite que docentes sem grau de mestre ou de doutor ministrem aulas regulares, ${ }^{15}$ o que aponta, na área jurídica, para o predomínio do praticismo em face da pesquisa e da carreira docente, muitas vezes repetindo os vícios que se identificam na atividade prática dos trabalhadores da área jurídica, sejam magistrados, promotores, advogados ou policiais - carreiras exclusivas de bacharéis em Direito. Da forma que está regulado, até mesmo práticos de

15 Portaria CAPES 60/19: Art. 10 O corpo docente dos programas de pós-graduação stricto sensu profissionais deverá ser composto por docentes permanentes e poderá incluir outras categorias, conforme legislação em vigor. $\S 1^{\circ} \mathrm{O}$ conjunto do corpo docente da proposta poderá incluir professores com experiência profissional acadêmica e não acadêmica, técnica, científica, de inovação e de orientação ou supervisão na área proposta. $\S 3^{\circ}$ Em conformidade com o previsto nos documentos orientadores de cada área de avaliação, poderão ser incluidos no corpo docente da proposta profissionais sem o título de mestre ou doutor, desde que denotem experiência reconhecida em pesquisa aplicada ao desenvolvimento e à inovação no segmento de atuação do programa proposto. I - O percentual máximo permitido para a situação prevista no caput do parágrafo terceiro será de $30 \%$ (trinta por cento). 
outras áreas podem ministrar aulas e formar mestres profissionais, e, ainda mais grave, doutores profissionais. Isso, na área jurídica, aponta para o naufrágio do Titanic.

A situação se torna ainda mais preocupante quando se verifica que não há efetivamente um padrão para o trabalho final de curso, pois as normas se referem vagamente a algo que não é nem uma dissertação e nem uma tese. ${ }^{16}$ Sendo um curso prático, profissionalizante, seriam admitidas petições iniciais? E sentenças? Votos proferidos em órgãos colegiados do Poder Judiciário? Pareceres dos órgãos ministeriais? Por que não um boletim de ocorrência bem elaborado? Ou uma escritura pública bem lavrada? Observe-se que esse contexto, pintado com cores fortes, aponta para os riscos inerentes à utilização de mestrados e doutorados profissionais na área do Direito.

Como acima referido, na área jurídica é adequado aliar o perfil profissional ao lado do acadêmico, pois permite unir os aspectos teóricos aos práticos, enriquecendo o processo de ensino-aprendizagem, e potencializando a pesquisa e os estudos pósgraduados. Foi referido também que é necessário que o docente saiba diferenciar sua posição enquanto profissional e acadêmico, pois possuem distintos perfis, evitando doutrinação profissional.

Esse ponto, doutrinação profissional, aponta para um risco exponencial na área jurídica, em razão da forma de estruturação de vários órgãos. Observe-se, por exemplo, o Poder Judiciário: serão gigantescas as chances de as posições dos que estão estruturalmente acima (Ministros, desembargadores) se tornarem dominantes em face dos que estão abaixo (juízes, desembargadores), afinal, está em jogo todo um sistema de carreira e ascensão profissional, no qual os membros dos Tribunais exercem um papel primordial e determinante. Sabendo-se que muitos dos membros dos Tribunais farão parte desses cursos profissionais, este risco está presente em concreto, afastando todo o debate doutrinário, e sobre o papel da doutrina e da pós-graduação nesse sistema, conforme exposto.

Existe ainda um silêncio eloquente na regulamentação desses cursos profissionais. É referido que tais títulos terão validade nacional, ${ }^{17}$ porém nem uma palavra é dita acerca da interrelação entre estes dois campos. Ou seja, um doutor profissional que foi formado sem os pressupostos acadêmicos, poderá ministrar aulas regulares em cursos de pós-graduação acadêmicos? Silêncio eloquente, que dá margem a muita judicialização, pois, inegavelmente, o grau obtido tem validade nacional.

16 Portaria CAPES 60/19: Art. 11 (...). Parágrafo único. O regulamento do programa Profissional deverá indicar os formatos dos trabalhos de conclusão, assim como os mecanismos de registro documentado sobre o conhecimento gerado pela pesquisa, para fins de verificação e avaliação.

17 Portaria CAPES 60/19: Art. 4 Os títulos de mestres e de doutores obtidos nos cursos profissionais avaliados positivamente pela CAPES, reconhecidos pela Câmara de Educação Superior do Conselho Nacional de Educação, CNE/CES, e homologados pelo Ministro da Educação, terão validade nacional. 
É bem verdade que a regulamentação da CAPES atribui à cada área do conhecimento estabelecer os parâmetros desses cursos profissionais, porém o nível de segurança jurídica desse mecanismo é muito frágil, pois diversos movimentos podem fazer refluir normas atualmente mais rigorosas em alterações que tornem os requisitos mais fluidos e fáceis - tudo em nome da expansão do ensino pós-graduado no Brasil. É um risco a ser considerado globalmente, para todo o sistema de pós-graduação em Direito no Brasil, com repercussões muito deletérias não só na área acadêmica, mas inclusive no âmbito profissional.

Infelizmente alguns PPGDs vêm trilhando esse caminho, que possui um ponto peculiar, que é a possibilidade de cobrança de mensalidades dos alunos, e, de certa forma, reforça o minguado salário dos docentes, mesmo os de IES públicas. ${ }^{18}$

Sob o meu ponto de vista, é um risco que não se está sendo medido adequadamente pela área como um todo, e leva a um passo adiante na metáfora antes exposta: o Titanic vai ao fundo com a orquestra tocando.

\section{h) Inclusão social e ações afirmativas no âmbito da pós-graduação em Direito}

Outro tópico extremamente importante diz respeito à necessária inclusão social de grupos vulnerabilizados na pós-graduação em Direito, o que possui direta conexão com o seu papel de locus de formação dos formadores, acima referido.

Basta observar o quadro docente dos cursos de graduação e pós-graduação em Direito e verificar sua completa desconexão com o perfil social e identitário existente. Quantos negros, mulheres ou pessoas com deficiências existem como docentes nas IES jurídicas? Considerando os percentuais existentes na sociedade, constata-se a desproporção mencionada.

Dados divulgados por Isabelle Oglouyan de Campos apontam que, “apesar de as alunas representarem aproximadamente $41 \%$ do número total de estudantes, as mulheres são apenas $18 \%$ do corpo docente". ${ }^{19}$ Observe-se que essa é apenas uma dimensão do problema existente, pois diz respeito ao acesso à docência, mas aponta para

18 Em 26/04/17, através do RE 597.854-GO, relatado pelo Ministro Edson Fachin, que, por sinal, foi representante da Área de Direito junto à CAPES (1999-2001), o STF decidiu que "a garantia constitucional da gratuidade de ensino não obsta a cobrança, por universidades públicas, de mensalidade em curso de especialização." Esta decisão se transformou no Tema 535 da Repercussão Geral. Observe-se que se trata de pós-graduação lato sensu, não se referindo especificamente a mestrados ou doutorados profissionais. Neste âmbito o assunto é controverso, existindo até mesmo a PEC 395/14 que busca regular o assunto.

19 CAMPOS, Isabelle Oglouyan de. Mulheres na Academia: desigualdades de gênero no corpo docente da Faculdade de Direito da USP. São Paulo: Cátedra UNESCO de Direito à Educação/Universidade de São Paulo, 2021. p. 4. Disponível em: https://unesdoc.unesco.org/ark:/48223/pf0000376046. Acesso em: 20 mar. 2021. 
toda a complexidade que deve ser objeto de análise e ultrapassagem, ainda mais quando se observa outros grupos vulnerabilizados.

Há uma inegável barreira para o acesso e para a permanência de alunos de populações vulnerabilizadas nos PPGD, impedindo que tenham condições de galgar posições docentes a partir dos graus de mestre e de doutor em Direito. Sem a ultrapassagem dessa barreira de acesso e também de permanência, será extremamente difícil conseguir modificar o perfil das Faculdades de Direito. E, com isso, também o das demais profissões jurídicas. Conta-se como exceção os membros do Poder Judiciário, Ministério Público, Polícias e advogados (públicos e privados) que pertencem a grupos vulnerabilizados. A reprodução da exclusão está presente, e o papel da pós-graduação para reverter esta situação é extremamente importante.

Nesse passo, o PPGD da USP aprovou em março de 2021 o PAF Programa de Ações Afirmativas a ser implementado para a inclusão de pessoas dos grupos de pretos, pardos, índios e pessoas com deficiência, consistindo, em breve síntese, na oferta de vagas extras por parte de docentes que se voluntariarem a aderir ao Programa. Esta vaga extra será vinculada ao preenchimento de pessoas pertencentes a esses grupos, e extinta, caso não preenchida. Isso afasta a ideia de quotas, pois não reduz o total de vagas existentes a serem oferecidas ao público em geral. Também reduz eventuais resistências ao só admitir nesse Programa de Ações Afirmativas os docentes que se voluntariarem, sem que haja nenhuma redução ou flexibilização de seus demais compromissos acadêmicos.

No âmbito da vulnerabilidade socioeconômica, para o acesso, serão seguidos os parâmetros legais, estabelecidos pelo Estado de São Paulo, para a gratuidade das taxas de inscrição aos exames, e, no âmbito da permanência, bolsas de estudos serão disponibilizadas - infelizmente, em número bastante aquém do necessário, porém superior ao dobro do que existia no início do quadriênio.

Outras medidas também foram previstas no âmbito do $P A F$, como a aquisição de leitores de textos para as pessoas com deficiência visual e instalações adequadas para as pessoas com deficiências motoras, além de seminários para o acolhimento dos ingressantes portadores dessas e outras vulnerabilidades.

Tudo isso será acompanhado por uma Comissão específica, criada especialmente para essa finalidade.

Com isso, segue-se o exemplo de outros PPGD que já adotaram medidas semelhantes, como o da USP de Ribeirão Preto e o da Universidade Federal do Pará, dentre outros. Os resultados surgirão a médio prazo, porém um primeiro passo já foi dado em busca de um PPGD-USP mais inclusivo. 


\section{i) A solidariedade entre os PPGDs em um país desigual}

O processo de inclusão, através de ações afirmativas acima referido não esgota todas as possibilidades de solidariedade que devem presidir os PPGDs, sendo necessário também serem formuladas políticas que reduzam as desigualdades sociais e regionais existentes, cumprindo assim mandamento constitucional (art. $3^{\circ}$, III).

Isso passa não só por projetos de pesquisa conjuntos, com a aproximação de linhas de pesquisa e corpos docente e discente, incluindo egressos, mas também com a criação de redes nacionais de pesquisa e produção acadêmicas em conjunto. Isso poderá potencializar estudos e soluções de problemas candentes de nosso país, permitindo que os PPGDs saiam de suas bolhas de conhecimento e potencializem o alcance de suas pesquisas acadêmicas. Um bom exemplo dessa dinâmica se identifica em concreto nos esforços que vem sendo realizados entre os PPGDs da UFC e da PUC-RS, no âmbito das análises jurídicas sobre energias renováveis, sendo possível listar vários outros.

Outra possibilidade de um agir solidário se verifica na iniciativa adotada pela Pro-Reitoria de Pós-Graduação da USP, através do Programa de Mobilidade Nacional (Resolução CoPGr No 7752, de 26 de junho de 2019), pelo qual é permitido a mestrandos e doutorandos de todo o país utilizar as instalações e participar de atividades acadêmicas em todos os âmbitos da Universidade. O PPGD da USP já regulamentou essas atividades e inclusive já recebeu mestrandos de outras Instituições no âmbito desse Programa.

Tais iniciativas passam também por atividades de extensão na pósgraduação, através das quais os Programas podem subsidiar iniciativas governamentais através de sugestões para aperfeiçoamento de políticas públicas ou projetos de novas normas a serem analisadas pelos Legislativos. As possibilidades neste campo são enormes, e devem ser incluídas no radar dos PPGDs.

Nesse contexto de solidariedade devem se inserir os esforços para a realização de MINTER e DINTER, que são iniciativas que envolvem a formação de quadros qualificados para a expansão do ensino de pós-graduação e para a pesquisa em locais que possuem baixa densidade acadêmica. Essas iniciativas devem primar pela qualidade dos estudos, mantendo igual nível ao do Programa de origem, outorgante dos graus de mestre e de doutor para aqueles discentes.

Um caso concreto, singelo e pontual, demonstra a necessidade desse tipo de solidariedade entre os PPGds, sem ser necessário descer a números, tabelas ou planilhas explicativas. Até o início da década de 90 do século passado no Brasil - isto é, antes de surgirem programas como MINTER ou DINTER -, só existiam cursos de Doutorado em Direito nas regiões Sul e Sudeste - quem desejasse aprofundar os estudos jurídicos deveria se deslocar para essas regiões. O primeiro doutorado em Direito fora do eixo Sul-Sudeste surge na década de 90, no âmbito do PPGD da UFPE - Universidade 
Federal de Pernambuco, composto por docentes daquela Universidade, em conjunto com outros docentes "visitantes" que possuíam vínculos com outras unidades de ensino espalhadas pelo Norte e Nordeste do país. Essa experiência bem-sucedida, ainda não relatada formalmente em livros ou artigos acadêmicos, contou inicialmente com docentes da Universidade Federal de Alagoas - UFAL, professores Paulo Luiz Netto Lobo e Andreas Krell; da Universidade Federal da Paraíba - UFPB, professor Eduardo Ramalho Rabenhorst; e com o autor destas linhas, então docente da Universidade Federal do Pará UFPA. O coordenador desse projeto pela UFPE foi o professor João Maurício Adeodato, ladeado pelo professor Ivo Dantas. Diversos outros docentes foram inseridos ao longo do tempo nesse projeto, como o professor Raymundo Juliano Feitosa. Essa iniciativa ampliou as oportunidades de ensino e pesquisa jurídicas no Brasil, gerando incontáveis PPGDs fora do eixo Sul-Sudeste, e aumentando a qualificação da produção docente.

Esses esforços devem buscar a ampliação das oportunidades de vida digna para cada indivíduo, onde quer que ele se encontre no território nacional. Isso não implica em dizer que deva haver um curso de pós-graduação em direito em cada cidade brasileira - definitivamente não é essa a intenção.

\section{j) Internacionalização dos PPGDs}

Outro aspecto deve ser destacado, que diz respeito à internacionalização dos PPGD. Muitas atividades vêm sendo desenvolvidas por todo o Brasil nesse âmbito, como palestras, seminários e outras atividades pontuais com docentes estrangeiros vindo ao Brasil, e missões acadêmicas isoladas em sentido contrário. $\mathrm{Na}$ prática, isso decorre muito mais de relações pessoais entre os docentes e seus contatos no exterior, do que através de uma estratégia acadêmica. Os PPGDs se valem desses contatos e avançam rumo à internacionalização, concedendo a essas iniciativas soladas seu apoio institucional.

A sugestão é para uma mudança de enfoque, sob duas perspectivas.

A primeira diz respeito ao planejamento estratégico que os PPGDs devem tomar no sentido de criar vínculos perenes com grupos de estudos em outras IES estrangeiros.

Quais linhas de pesquisa unem os grupos? Quais projetos acadêmicos conjuntos podem ser desenvolvidos? Não se trata de uma palestra ou aula de um docente de cá ou de lá, no Programa recíproco, mas de uma efetividade de publicações conjuntas em que se possa refletir sobre o estado da arte de um determinado ponto específico em cada país ou ordenamento. Exemplos podem tornar a ideia de mais fácil compreensão. Através da Lei 13.104/15 foi tipificado no Brasil o crime de feminicídio. Como esse tipo criminal aqui referido é tratado pela legislação, doutrina e jurisprudência de Portugal ou Espanha? Haverá a necessidade de tipificação para tais condutas, ou outro tipo penal 
comporta sua tipificação como agravante? Aqui haverá um campo enorme para pesquisas conjuntas, envolvendo diferentes grupos de pesquisa, com docentes, discentes e egressos, de diversos países. Os exemplos poderiam ser multiplicados ao infinito.

O que se propõe é a condução estratégica pelos PPGDs voltadas à internacionalização de suas linhas e projetos de pesquisa, e não fazer isso de forma isolada, através de louváveis iniciativas docentes. A identificação desse tipo de grupos mundo afora seguramente ocorrerá através dos docentes, porém é necessário envolver um maior grupo de pessoas, a fim de que tais iniciativas não fiquem restritas àquilo que pejorativamente é identificado como turismo acadêmico. Os vínculos devem ser perenizados, de tal forma que os intercâmbios se tornem uma estrutura dos Programas, envolvendo não só os docentes, mas também dos discentes, e isso se reflita na produção acadêmica, que, então, poderá ser internacionalizada, caso reflitam esse entrelaçamento. Outras áreas do conhecimento já adotam esse tipo de planejamento estratégico com muito bom resultado, como nas ciências exatas e naturais. A área de Direito deve se voltar a isso.

Por outro lado, e especificamente para a área jurídica, constata-se ser muito comum que os esforços de internacionalização mirem os países europeus e os Estados Unidos da América, a depender da área de estudo. Porém, muitas vezes, essa internacionalização reproduz assimetrias, se verificando uma via de mão única, com os colegas estrangeiros reproduzindo seu conhecimento para os brasileiros, e pouco interessados com o que se realiza e o que se pensa sobre o Direito a partir de nosso país. Isso ocorre sejam os estrangeiros visitantes no Brasil, ou os brasileiros como visitantes. São hauridos conhecimentos sob a forma de mão única, sem haver entrelaçamento de informações, sem troca efetiva.

Isso se comprova pela baixíssima citação de autores brasileiros em publicações estrangeiras. Os brasileiros podem até publicar no estrangeiro, mas o nível de citação de suas publicações é baixo, em especial se compararmos com as citações feitas por brasileiros de obras de autores estrangeiros. Isso aponta para a assimetria acima referida.

Uma alternativa a isso, seria reforçar os laços com os países sul-americanos e da África portuguesa, com os quais temos muitas proximidades históricas, porém pouco envolvimento acadêmico efetivo. Para tanto, é necessário um esforço adicional dos PPGDs, pois, sem perder de vista o que já é feito, deve-se voltar os olhos para essas novas fronteiras geográficas de divulgação do saber e da cultura jurídica brasileira.

Constata-se que os países de língua portuguesa ainda têm em Portugal o centro do saber jurídico, reproduzindo-o através de laços de cooperação acadêmica; o mesmo ocorre com os países de língua espanhola, em relação com a Espanha. Caso haja um esforço dos PPGDs nesse sentido, é possível criar e disseminar a cultura jurídica 
brasileira nesses países, divulgando nosso Direito e modificando o perfil eurocentrista atualmente existente.

Essa ótica passa por missões acadêmicas junto a esses países, e por aulas e seminários em espanhol, mesmo que seja em território brasileiro. Para os países da África portuguesa esse problema seria minimizado. Maior ousadia seria adotar o idioma inglês, atual língua franca científica mundial, porém, no atual estágio de desenvolvimento de nossos Programas, se o esforço fosse centrado no idioma espanhol, com foco nos países circunvizinhos, já haveria um salto enorme rumo à efetiva internacionalização.

Claro que além de ser necessário organizar internamente os Programas nesse sentido, é preciso realizar missões acadêmicas a esses países, a fim de estreitar laços e criar vínculos, semelhantes aos que existem com os países europeus e os Estados Unidos, porém sem repetir o erro da assimetria acima relatada. É necessário que o intercâmbio de pessoas (docentes, discentes e egressos) e ideias ocorra em mão dupla, a fim de que países que possuem tradições e perfil socioeconômico semelhante ao brasileiro possam, de comum acordo, contribuir para o desenvolvimento de seus institutos e saberes jurídicos.

Conclusões

Resumindo uma longa história, pode-se afirmar que o Parecer Sucupira, 50 anos atrás, estabeleceu as linhas mestras da pós-graduação no Brasil, e isso impactou fortemente todas as áreas do conhecimento, incluindo a área jurídica. Os PPGD se estruturaram segundo suas diretrizes, sendo que o PPGD-USP, que também comemora 50 anos ininterruptos de atividade, foi a alma mater da esmagadora maioria dos Programas existentes no Brasil, cujo número já ultrapassou o de uma centena.

Ao longo desses anos, através da criação dos graus de mestre e de doutor foi estruturada uma carreira docente, cujo destaque se dá nos PPGD, que se tornaram o local de formação dos formadores, isto é, dos docentes que estruturarão os cursos de graduação em Direito, pelos quais obrigatoriamente passarão pessoas que compõem os pilares do Estado: Poder Judiciário, Ministério Públicos, os diversos âmbitos da advocacia e o aparato policial, além de formar profissionais para outras profissões não exclusivas da área jurídica. Com isso, a importância e o poder de influência dos estudos pós-graduados ganham outra dinâmica, pois agem decisivamente na formação dos futuros docentes que comporão as faculdades de Direito.

A despeito da qualidade identificada ao longo desses anos, algumas sugestões são apresentadas com a finalidade de melhorar a atuação e o alcance dos PPGDs, tais como: 
a) A reafirmação da posição doutrinária em face das decisões dos Tribunais, através da qual se deve considerar a jurisprudência como um campo de estudos, mas não como o Direito pleno e acabado, que não admita contestações doutrinárias;

b) Deve-se voltar o olhar para a pesquisa aplicada, sem esquecer da pesquisa pura, o que passa pela reanálise dos métodos aplicados aos trabalhos acadêmicos;

c) É adequada a organização dos PPGDs através de áreas e linhas de pesquisa, e não por departamentos, pois permite maior flexibilidade acadêmica;

d) Deve-se buscar a valorização de estudos pluridisciplinares, em suas diversas dimensões, conectados ao ensino e à pesquisa jurídicas, evitando a entropia;

e) E necessário revalorizar a divulgação através revistas científicas, a despeito da tradição da divulgação de livros na área jurídica;

f) Deve-se ter cautela com a expansão acelerada de PPGDs, pois isso leva à desvalorização das credenciais acadêmicas, podendo também levar à queda de qualidade da produção;

g) A adoção de cursos profissionalizantes pela área jurídica, mestrados e doutorados profissionais, é muito preocupante, e pode gerar problemas de monta tanto na área acadêmica, quanto nos diversos segmentos profissionais ínsitos às carreiras jurídicas;

h) É papel dos PPGDs realizar inclusão social, adotando ações afirmativas, visando modificar o perfil socioeconômico e identitário dos profissionais da áreas jurídica: juízes, promotores, policiais etc., e, em especial, os novos docentes das faculdades de Direito. O PPGD-USP iniciou projeto nesse sentido, denominado PAF - Programa de Ações Afirmativas;

i) Espera-se também dos PPGDs a adoção de atitudes solidárias no âmbito de um país marcado por desigualdades sociais e regionais; e,

j) Devem também os PPGDs terem os olhos voltados à internacionalização, em especial para os países de língua portuguesa e espanhola, com efetiva atuação de mão dupla, o que nem sempre ocorre nos intercâmbios europeus e norteamericanos.

Enfim, a despeito de muito já ter sido feito nestes 50 anos, existem novos desafios a serem vencidos pelos PPGDs, cujas ações devem ser apoiadas pelos órgãos acadêmicos centrais de cada IES, pelas agências financiadoras e pela agência reguladora (CAPES), com os olhos voltados à expansão da qualidade e à importância dos estudos jurídicos que são desenvolvidos em nosso país. 